\title{
Median RR Duration
}

National Cancer Institute

\section{Source}

National Cancer Institute. Median RR Duration. NCI Thesaurus. Code C102254.

A measurement of the median duration (time) of the RR interval, obtained from a set of measurements of the RR interval. The RR interval is defined as the time between successive peaks of the $\mathrm{R}$ wave and can be used to measure the ventricular rate. 